\title{
Social Interaction Determinants of South African Reading Literacy Achievement: Evidence from prePIRLS 2011
}

\author{
Annika Bergbauer \\ Ifo Institute, Munich, Germany, bergbauer@ifo.de
}

\section{Surette van Staden}

Department Science, University of Pretoria, South Africa, surette.vanstaden@up.ac.za

This study identifies factors predicting reading literacy achievement among Grade 4 students in South Africa by utilizing Vygotsky's social interaction theory. The study draws on the preProgress in International Reading Literacy Study (prePIRLS) 2011 data, which places South African Grade 4 students' results below the international centre point of 500 at 461 . For the current analysis, distinct items from the prePIRLS 2011 parent, student, and teacher questionnaires predict learning outcomes significantly, including parents talking to students about school and assisting with homework, teachers' degree of success in implementing the school's curriculum, and student responses on how clear teacher expectations are. Findings explain $41 \%$ of the variance in student reading achievement and provide evidence for the significant role of teachers and parents in predicting increased reading literacy achievement scores. An absence of interaction with the child in either parents who do not engage in homework activities or talking about school, teachers who do not successfully implement the curriculum or make their expectations clear to students link statistically significantly to lower reading literacy achievement scores. Achievement for Grade 4 students who were tested in African languages was adversely worse than those students by test language.

Keywords: Vygotsky's social interaction theory, contextual factors, social interaction, prePIRLS 2011, reading literacy achievement

\section{INTRODUCTION}

Children's educational achievement is not just dependent on their own efforts or discoveries, but the result of culturally-situated social interaction (Mercer and Howe, 2012). From a socio-cultural perspective, knowledge is created by members of communities, referred to by Mercer and Howe (2012) as 'cultural tools' (such as spoken and written language) relationships and institutions, such as schools, and for a specific purpose. Triplett (2007) describes the student as a reader as "a socially constructed subjectivity or identity that begins in the early grades." (Triplett, 2007:98).

Citation: Bergbauer, A., \& Staden, S. V. (2018). Social Interaction Determinants of South African Reading Literacy Achievement: Evidence from prePIRLS 2011. International Journal of Instruction, 11(2), 555-568. https://doi.org/10.12973/iji.2018.11238a 
In order to explore issues of sociocultural theory, this study draws on selected contextual variables of the preProgress in International Reading Literacy Study (prePIRLS) 2011 South African data to determine the extent to which students' parents talk to them about school, and assist with homework. In addition, the extent to which teachers characterized the degree of success in implementing the school's curriculum, and the extent to which students know what their teachers expect of them provide additional indicators of the sociocultural aspect of the current analyses. These variables, although not exhaustive of the variables across the prePIRLS 2011 questionnaires that could indicate social interaction, forms part of the possible effects against which a sociocultural perspective of reading literacy achievement can be made. This study combines theoretical ideas from psychology with empirical evidence based on econometric methods. Hence, its contribution lies in identifying the gap of measuring the size of social determinant coefficient regressed on learning outcomes and the relative importance of social determinants compared with other learning process inputs.

\section{Theoretical Background}

In relating social interaction and cognitive achievement, this study employs employ Vygotsky's social interaction theory (Vygotsky, 1962; Vygotsky, 1978). Figure 1 depicts the structure of the model:

Cultural context

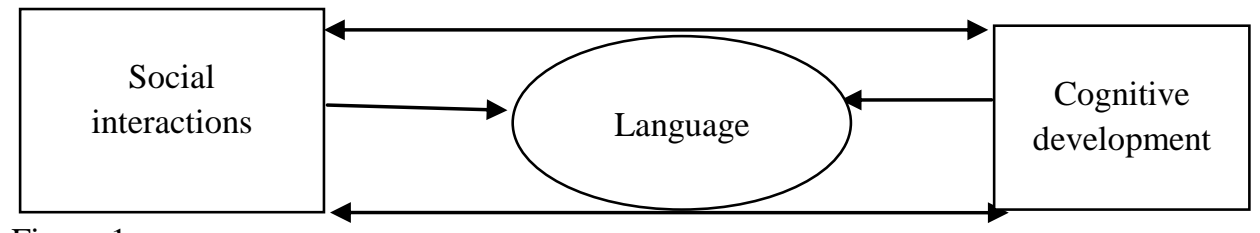

Figure 1

Vygotsky's sociocultural theory populated with prePIRLS2011 variables

For purposes of the current study, the interest lies specifically in the role of social interactions.

Different disciplines have approached the social setting of learning by distinguished methods. Within economics, key concepts in non-cognitive skills including social dimensions were proposed by Heckman, Stixrud and Uruza, (2006). Here, the scholars measured social outcomes, such as the likelihood to be incarcerated, teen pregnancy, high school drop-out, college graduation, smoking, and wages. In further work, Cunha, Heckman, Lochner and Masterov (2006) constructed an anti-social behaviour index within the analysis of life cycle skill formation. Here, they defined strong families as based on an enriched parental environment, such as the mother's education and ability, family structure and income. Similarly, McLanahan (2004) uses time devoted to child development activities and coin the term "intact families" - defined by single motherhood, employment and age at first birth of the child, and mother's education status. Furthermore, Edwards, Anda, Dube, Dong, Chapman and Felitti (2005) describe adverse childhood experience in their investigation of domestic violence, medical or social problems (substance abuse, mental illness, parental loss, crime in the home, etc.) based on a long-term study of 17,337 participants born in the 1900s. 
In contrast, social settings may be used as determinants of learning outcomes. Various economists employed social settings for their analyses (Bianchi, Robinson, and Milkie (2006) use time devoted to child rearing, time reading to children or TV time. Bradley and Corwyn (2002) employed cognitively stimulating experiences and materials, while Saegert and Winkel (1990) focused on learning opportunities for continued learning. In their work, Ford and Lerner (1992) regarded opportunities for learning and social exchange from a developmental systems perspective.

Gonzalez-DeHass, Willems and Holbein (2005) examined the role of parental involvement and student motivation and extract from previous research that student outcomes across different phases are improved when the family is actively involved, specifically in the early grades in activities ranging from the students' sense of wellbeing, school attendance, attitude, homework readiness, grades and educational aspirations. Gonzalez et al. (2005) refer specifically to the work done by Adunyarittigun (1997), who investigated the link of a parental volunteer program on Grade 4 and Grade 6 children's self-perceptions as readers. Results from this study suggest that parental involvement was related to greater confidence and self-efficacy as readers, increased motivation to read and greater involvement in literacy activities. Potential transmission channels may have been that parents were viewed as role models and trusted partners in helping students assess their own competences and performance, while parental support provided self-confidence to persist in tasks that may be challenging.

Jeynes (2005) conducted a meta-analysis of research on parental involvement and its role in urban elementary school student achievement. Student achievement as outcome variable was composed of different measures of academic achievement, namely the overall measure of all components of academic achievement, grades, academic achievement from standardized tests, and teacher rating scales and indices of academic behavior and attitude. Jeynes (2005) found that parents who checked their children's homework did not reveal statistically significant advantages for student learning. However, overall, parental involvement and academic outcomes showed strong links and seemed to transcend socio-economic status (SES), race and gender. Work of Patall, Cooper and Robinson (2008) and Hansen and Quintero (2017) portray a slightly more complex relationship between parental involvement, homework and student achievement. For example, Patall et al. (2008) found non-linear relationships among numerous factors, including the involvement strategy the parents use, the child's age and ability level, resources in the home and the parents' own mentoring skills.

The emphasis that schools place on the curriculum forms part of the current analysis. In its simplest form, curriculum refers to the planning of what is to be taught, learnt, its implementation and evaluation, but as stated by Graves (2008), curriculum is also the product of someone's reasoning about what education is, whom it should serve and how. Edwards (2003) describe curriculum as a human endeavour that involves cultural beliefs, values, languages and theories, thereby making it an inherent social product steeped in psychology and what is known about how children acquire knowledge. Graves (2008) embeds curriculum in social and educational contexts that determine their purpose and scope. So, for example, is the classroom the place where the language curriculum happens. Yet, the classroom is not an isolated environment or only a physical 
place, but is rooted in complex and overlapping cultural, social, educational and political contexts. Classrooms are communities of people involved in social systems with explicit norms, hierarchies and values (Graves, 2008). Therefore, the classroom itself is a sociocultural context and social environment with its own systems, norms and values, where the curriculum is enacted.

The current analyses also draws on teachers' expectations of student learning. RubieDavis, Hattie and Hamilton (2006) state that such expectations may become evident in the learning opportunities that are provided, in the affective climate of the classroom and the interactional content and context of the classroom. Individual student characteristics have been identified as possibly associated with teacher expectations, namely gender, ethnicity, social class, stereotypes, diagnostic labels, physical appearance, language, student age, personality, social skills other siblings or one-parent background. The work of Diamond, Randolph and Spillane (2004) provides evidence that specifically in lower income schools, expectations are lower, resulting in a decreased sense of responsibility for students. Social interaction features in the work of Diamond et al (2004), who state that collective responsibility for student learning is an organizational indicator of teachers' expectations. In schools with a high degree of collective responsibility, students reach greater achievement gains. According to Diamond et al (2004), schools function on a continuum, ranging between those schools where teachers take responsibility for the success or failure of their teaching, and those schools where teachers see obstructions between themselves and their students, for example students' abilities, family background or lack of motivation.

Participation in international comparative assessments have allowed researchers to draw conclusions about student achievement in relation to various background factors related to the school, the classroom environment, the students themselves and their home environments. Studies on the factors associated with learner performance, using PIRLS 2006 data, have been conducted by Frank and Rosen (2008) in Sweden, Geske and Ozola (2008) in Latvia and van Daal, Begnum, Solheim and Ader (2008) in the Nordic countries and van Staden (2011) in South Africa. The work of Lee, Zuze and Ross (2005) in their secondary analysis of the Southern and Eastern African Consortium for Monitoring Educational Quality (SACMEQ II) data showed patterns of higher achievement in schools with more resources and higher quality teachers. Prinsloo and Stein's (2004) study of South African teachers, point out that an aspect of teacher quality is the teacher's ability to function in complex communicative environments in which the differences in children's literacy experiences result from how the teachers invent their activities around literacy differently, despite following the same 'broad' curriculum.

Donald, Condy and Forrester (2003) report that despite structural transformations that have taken place in post-apartheid South African society and its education system, many schools still face educational disadvantages, making the adequate development of literacy skills a national priority. Generally under-resourced schools, extensive poverty, unemployment and teacher under-qualification result in generally low standards of scholastic progress, achievement, high failure and attrition rates, and hence in inadequate development of literacy for the learners concerned. It should therefore come 
as no surprise that consistently poor student achievement is evident in South Africa's track record in international assessments. South African students' poor performance in reading literacy was first evidenced by the Progress in International Reading Literacy Study (PIRLS) 2006 results. In PIRLS 2011, South Africa elected to participate in the preProgress in International Reading Literacy Study (prePIRLS) 2011 where Grade 4 students were assessed across all 11 official languages. As a less difficult version of PIRLS, prePIRLS allows developing countries to assess children's reading comprehension with shorter texts, easier vocabulary, simpler grammar and less emphasis on higher-order reading skills (Mullis, Martin, Foy, and Drucker 2012). PrePIRLS is designed to test basic reading skills that are prerequisites for success in PIRLS (Mullis et al., 2012).

PrePIRLS 2011 results point to continued underperformance by South African students with little evidence of improved reading literacy scores, even when administering an easier assessment (Mullis et al., 2012). The prePIRLS 2011 study results revealed that South African Grade 4 students obtained 461 (SE=3.7), the lowest reading achievement score in comparison with the international centre point of 500. In contrast, students from Botswana achieved $463(\mathrm{SE}=3.5)$ while students from Colombia obtained $576(\mathrm{SE}=3.4)$ (Mullis et al., 2012). While the current analyses focus on prePIRLS 2011 results, the results from PIRLS 2016 have been released in December 2017. In these results, South African Grade 4 student performance yet again disappoints in the PIRLS 2016 Literacy study (called prePIRLS in the 2011 cycle) with overall lowest performance at 320 points ( $\mathrm{SE}=4.4$ ) (Howie, Combrinck, Roux, Tshele, Mokoena and Palane, 2017). While newly released PIRLS 2016 results are mentioned here and available for analyses, these data were not yet available at the time of submitting this manuscript for publication.

For purposes of measuring reading literacy achievement in the current analyses, the PIRLS definition is used and refers to

...the ability to understand and use those written language forms required by society and [or] valued by the individual. Young readers can construct meaning from a variety of texts. They read to learn, to participate in communities of readers and for enjoyment. (Mullis, Martin, Kennedy, Trong and Sainsbury, 2009:11).

With this definition, as it applies to prePIRLS 2011 (Mullis et al., 2009) reading literacy is regarded as a constructive and interactive process. According to Brinkley and Kelly (2003), the reader is regarded as actively constructing meaning and applying effective reading strategies. Such readers have positive attitudes towards reading and read for the purposes of information acquisition as well as recreation. Meaning is constructed in the interaction between reader and text, in the context of a particular reading experience. Reading implies that readers bring with them and apply a repertoire of knowledge, skills, cognitive and metacognitive strategies during reading.

Fuchs and Woessmann (2004) refer to the definition of reading literacy offered by the Organization for Economic Co-operation and Development (OECD), as the capacity to understand, use and reflect on written texts in order to achieve one's goals, to develop one's knowledge and potential and to participate in society. Reading literacy is therefore 
not understood as a basic skill, but rather as a goal, while at the same time also being a functional means of education and individual development, within and outside school, in the individual's current and later life, in further education, at work and in leisure activities (Linnakyla, Malin \& Taube, 2004). Viewing literacy as a social practice means that reading represents a multitude of evolving human activities with language at its centre (Landis, 2003). According to Frost, Madsbjerg, Niedersee, Olofsson and Sorensen (2005) reading is an activity used for interpersonal communication, but is also dependent on intrapersonal sources such as motivation, attention, imagination, memory, comprehension and language. In 1991, Hiebert offered a constructivist approach to the definition of literacy by stating:

'For some time now, a new perspective on literacy and the learning processes through which literacy is acquired have been emerging. This new perspective does not consist of old ideas with a new name, but rather it represents a profound shift from a text-driven definition of literacy to a view of literacy as active transformation of texts. In the old view, meaning was assumed to reside primarily within text, whereas, in the new view, meaning is created through an interaction of reader and text (Hiebert, 1991:1).

In the current study, an interaction between reader, text and the social setting of learning is, as mediated by the parents, the teacher and the curriculum, is argued.

\section{METHOD}

\section{Research Design}

Originally, PrePIRLS 2011 is an international comparative survey of reading literacy conducted with Grade 4 children. The study is run under the auspices of the International Association for the Evaluation of Educational Achievement (IEA), and prePIRLS 2011 offered developing countries the opportunity to test reading literacy at an easier level than PIRLS while utilising the same conception of reading literacy. For purposes of this study, a secondary analysis design of South African prePIRLS 2011 data was conducted to test the extent to which reading literacy achievement can be predicted using Vygotsky's sociocultural theory (1962, 1978). Specifically, parents talking to their children about school and checking homework, the extent to which teachers characterized the degree of success in implementing the school's curriculum, and student awareness of teacher expectations were analysed to predict reading literacy achievement.

\section{Participants}

A nationally representative sample of 15,744 Grade 4 students from 342 schools participated in the prePIRLS 2011 study in South Africa (Howie, van Staden, Tshele, Dowse and Zimmerman, 2012). The sample consisted of 7,548 girls and 8,196 boys. Students were assessed across all 11 official languages and were assessed in the Language of Learning and Teaching (LoLT) to which they were exposed in Foundation Phase. This means that learners were not necessarily tested in their home language, but rather in the language they were exposed to at school between Grade 1 and Grade 3. The stratification by language resulted in the following attained sample: 
Table 1

Number of Grade 4 prePIRLS 2011 students tested by language

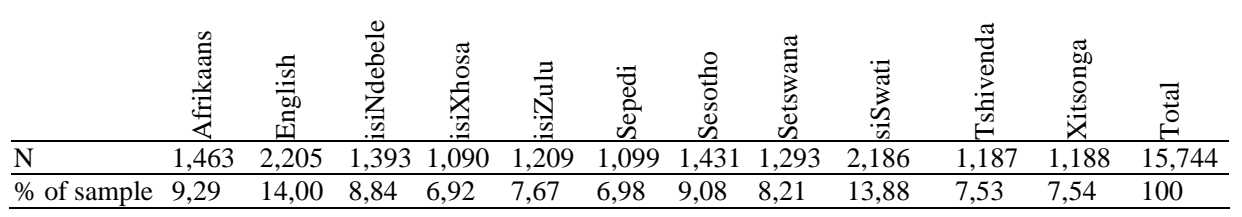

For purposes of the current analyses, achievement data and background questionnaire data from the 8,713 students, after removing missing values, were used.

\section{Data Collection}

\section{Achievement tests}

The prePIRLS 2011 assessment consisted of a reading literacy test in the form of two types of texts, namely reading for literary experience (or literary texts) and reading to acquire and use information (or informational texts). Reading texts were followed by multiple choice questions and open response questions to a maximum of three points. All questions corresponded to any one of the four types of reading comprehension process, namely (1) focus on and retrieve explicitly stated information, (2) making straightforward inferences, (3) interpret and integrate ideas and information and (4) examine and evaluate content, language and textual elements. Reporting of reading achievement results in prePIRLS 2011 are presented in terms of overall achievement above or below the fixed international centre point of 500 through the use of five overall Plausible Values as derived from Item Response analyses.

\section{Background Questionnaires}

Grade 4 students, their parents, teachers of the Grade 4 students and school principals responded to contextual background questionnaires. Table 2 presents variables that were selected for the current analyses.

Table 2

Selection of variables from the prePIRLS 2011 parent, teacher and student questionnaires.

\begin{tabular}{|c|c|c|}
\hline Question & Source & Response options \\
\hline $\begin{array}{l}\text { Parents talk to } \\
\text { students about } \\
\text { schoolwork }\end{array}$ & $\begin{array}{l}\text { Learning-to- } \\
\text { read survey } \\
\text { (parent } \\
\text { questionnaire) }\end{array}$ & $\begin{array}{l}\text { Grade } 4 \text { students' parents were asked the frequency with which they } \\
\text { talked to their child about schoolwork (variable ASBH09A). } \\
\text { Response options ranged from every day or almost every day, once or } \\
\text { twice a week, once or twice a month and never or almost never. }\end{array}$ \\
\hline $\begin{array}{l}\text { Parents check } \\
\text { homework }\end{array}$ & $\begin{array}{l}\text { Learning-to- } \\
\text { read survey } \\
\text { (parent } \\
\text { questionnaire) }\end{array}$ & $\begin{array}{l}\text { Grade } 4 \text { students' parents were asked the frequency with which they } \\
\text { checked their homework (variable ASBH09E). Again, response } \\
\text { options ranged from every day or almost every day, once or twice a } \\
\text { week, once or twice a month and never or almost never. }\end{array}$ \\
\hline $\begin{array}{l}\text { Teachers' emphasis } \\
\text { on the curriculum }\end{array}$ & $\begin{array}{l}\text { Teacher } \\
\text { questionnaire }\end{array}$ & $\begin{array}{l}\text { Teachers were asked the extent to which they characterized the } \\
\text { degree of success in implementing the school's curriculum (variable } \\
\text { ATBG06C). Response options included very high, high, medium, } \\
\text { low and very low. }\end{array}$ \\
\hline $\begin{array}{l}\text { Students know what } \\
\text { their teachers expect } \\
\text { of them }\end{array}$ & $\begin{array}{l}\text { Student } \\
\text { questionnaire }\end{array}$ & $\begin{array}{l}\text { Students were asked their agreement in terms of knowing what their } \\
\text { teachers expected of them (variable ASBR05C). Student responses } \\
\text { were recorded as agree a lot, agree a little, disagree a little and } \\
\text { disagree a lot. }\end{array}$ \\
\hline
\end{tabular}




\section{Data Analysis}

For purposes of generating descriptive statistics for the variables used in this investigation, the International Database Analyser (IDB) was used. The IDB Analyzer is a plug-in for the Statistical Package for the Social Sciences (SPSS) and was developed by the IEA's Data Processing and Research Centre.

Stata version 13.0 was used to control for student characteristics in an Ordinary Least Squares (OLS) regression analysis. The estimation strategy that was followed was:

Test score $=\alpha+\beta$ LANGUAGE $_{i}+\gamma$ SCHOOL $_{j}+\delta$ FAMILY $_{k}+\mu$ STUDENT $_{l}+\varepsilon$

Evans and Schwab (1995); Andrabi, Das, Khwaja \& Zajonc (2011) and Deming, Hastings, Kane \& Staiger (2014) justify the use of OLS. The prePIRLS 2011 survey design produced five randomly assigned booklets yield similarly distributed plausible values of reading achievement. The first plausible value is chosen as dependent variable, while the other four plausible values are used for robustness checks. Test language $i$ is either English or one of the African languages linked to one or another tier of South Africa's bi-modal education quality. School variables $j$ include school-level learning inputs, in this case, teachers' emphasis on the curriculum. Family attributes $k$ refer to involvement in schoolwork. Individual student characteristics $l$ encompass gender, age, and socio economic attributes. Those controls aid controlling for endogeineity issues. Higher student achievement may be caused by more apt students attending higher quality schools, or students of higher socio-economic levels attending higher quality schools. Hence, school choice would be non-random biasing OLS estimates and correlating error terms. For internal validity, school quality, non-random school choice, and initial starting conditions are accounted for. As stated earlier, school socio economic status and school quality are not random. Students of higher socio-economic status are suspected to self-select into higher-quality schools in search for higher learning outcomes, while more apt students may opt for higher-quality schools. Both endogeneities violate OLS assumptions and may lead to biased coefficients of school quality. To control for school quality, average school assets are included as explanatory variable. Furthermore, explicit and implicit stratification of the prePIRLS 2011 sampling design provides nationally representative samples across school type and language of instruction. Additionally, probability weights account for lower student heteroscedasticity. Frequency weights compensate for school clustering. With regression analysis clustered on school level, robust standard errors are yielded.

\section{FINDINGS}

\section{Summary of Descriptive Statistics for Variables Used in the Current Analyses}

Parents of Grade 4 students were asked how often they talked to their children about school or checked their homework. More than two thirds of parents of Grade 4 students indicated their involvement in talking with their children about school and checking homework. Teachers of Grade 4 students were asked to what degree they would characterize the success of implementation of the curriculum ranging from very high, high, medium, low and very low. Here, $51.46 \%(\mathrm{SE}=3.22)$ of teachers of Grade 4 students rated their success of curricular implementation as high, with only $13.63 \%$ 
$(\mathrm{SE}=2.21)$ as very high and a majority of $33.73 \%(\mathrm{SE}=3.26)$ as medium. Lastly, Grade 4 students were asked the extent to which they knew what their teacher expected of them. A majority of 66.48 ( $\mathrm{SE}=1.02)$ Grade 4 students indicated that they agreed a lot with the statement, followed by $18.34 \%$ ( $\mathrm{SE}=0.54)$ who only agreed a little with this statement. An additional $8.69 \%(\mathrm{SE}=0.51)$ and $6.50(\mathrm{SE}=0.41)$ disagreed a little and a lot respectively, indicating that they did not always know what their teachers expected of them.

\section{Regression results}

Regression results in Table 3 provide coefficients for each of the variables utilized in the current analysis, followed by coefficients for controls for student characteristics, assets, and test language $(\mathrm{N}=8,713)$. English test language is used as reference group against which all comparisons are made.

Table 3

Results for possible effects of teachers, schools and parents on reading literacy achievement

\begin{tabular}{lll}
\hline Variables & Coefficient & SE \\
\hline Parents talk about school once or twice a week & -1.187 & 2.036 \\
Parents talk about school once or twice a month & $-10.72^{* * * *}$ & 3.638 \\
Parents never talk about school & -5.995 & 4.764 \\
Parents check homework every day & $21.70^{* * *}$ & 2.256 \\
Parents check homework once a week & $16.28^{* * *}$ & 2.868 \\
School emphasis on curriculum: High & $-16.25^{* *}$ & 6.609 \\
School emphasis on curriculum: Medium & $-13.79^{* *}$ & 6.831 \\
School emphasis on curriculum: Low & $-41.12^{* * *}$ & 9.869 \\
Students agree a little they know what teacher expects & $-11.26^{* * *}$ & 2.058 \\
Students disagree a little they know what teacher expects & $-27.33^{* * *}$ & 2.927 \\
Students disagree a lot they know what teacher expects & $-9.745^{* * *}$ & 3.145 \\
Test language Afrikaans & 6.518 & 9.186 \\
Test language: isiNdebele & $-58.99^{* * *}$ & 8.373 \\
Test language: isiXhosa & $-31.63^{* * *}$ & 11.71 \\
Test language: isiZulu & $-43.44^{* * *}$ & 12.43 \\
Test language: Sepedi & $-84.17^{* * *}$ & 8.831 \\
Test language: Sesotho & $-46.68^{* * *}$ & 10.28 \\
Test language: Setswana & $-58.62^{* * *}$ & 8.471 \\
Test language: SiSwati & $-61.63^{* * *}$ & 7.281 \\
Test language: Tshivenda & $-75.58^{* * *}$ & 14.76 \\
Test language: Xitsonga & $-70.66^{* * * *}$ & 9.060 \\
Student age & $-8.159^{* * *}$ & 0.969 \\
Student gender (female) & $23.89^{* * *}$ & 1.602 \\
Asset scale & $2.052^{* * *}$ & 0.581 \\
Asset scale & $-0.503^{2}$ & 0.286 \\
School assets & $19.52^{* * *}$ & 2.890 \\
Constant & 575.4 & 17.26 \\
Observations & 8713 & \\
R-squared & 0.412 & \\
\hline$* * *$ p<0.01, ** p<0.05, $*<0.1$ & & \\
Stand & &
\end{tabular}

Standard errors are clustered on school level. 
Across all the African languages (except for Afrikaans), African test language predicts significantly lower results as compared to English. As mentioned earlier, it has to be kept in mind that the language in which students were tested in prePIRLS 2011 did not necessarily coincide with the home language. Nevertheless, the statistically significant lower results across all African languages still provide stark evidence for disappointingly low reading literacy achievement even for students tested in a language to which they were exposed between Grades 1 and 3. All of the student control variables show significant coefficients at the 0.01 level, except where the student asset scale was squared which was only statistically significant at the 0.1 level. Squaring the student asset scale is done when expecting that after a certain threshold of assets additional assets do not have any effect on test scores.

In terms of testing for the social interaction of parents and children, parents talking to their children about school and checking homework were used. Here, the reference category is parents who talk to their child about school every day and who never checks homework. Table 2 indicates a statistically significant disadvantage for students to whom parents talk about school once or twice a month as opposed to every day by 10.72 ( $\mathrm{SE}=3.638$ ) points. Similarly, students of parents checking homework every day expose a statistically highly significant advantage over never checking by 21.70 $(\mathrm{SE}=2.256)$ points. Even less frequent homework checks once a week results in an advantage of 16.28 points ( $\mathrm{SE}=2.868$ ).

Social interaction of teachers and children in terms of teachers' emphasis on implementing the curriculum exposes a statistically highly significant advantage in literacy scores for very high curriculum adherence opposed to high levels (measuring 16.25 points, $\mathrm{SE}=6.609$ ), medium emphasis (measuring -13.79 points, $\mathrm{SE}=6.831$ ) and low emphasis by as much as -41.12 .7 points $(\mathrm{SE}=9.869)$. Although very low was included in the item as a response option, none of the teachers of Grade 4 students chose this option. Lastly, students who know exactly what their teachers expect opposed to students a little that they know what is expected, students who disagree a little and disagree a lot that they know what is expected associate statistically highly significantly at the 0.01 level with -11.26 points ( $\mathrm{SE}=2.058),-27.33$ points ( $\mathrm{SE}=2.927)$, and -9.745 points $(\mathrm{SE}=3.145$ ) lower literacy scores respectively.

Evidence from the current study shows that social interaction variables expose statistically highly significant estimates of literacy achievement and highlight the importance of soft factors in learning. Overall, the model explains $41 \%$ of the variance in student reading literacy achievement. It has to be kept in mind that not all variables across the different background questionnaires that are related to social interaction were utilized in the current analyses - instead, the current analyses provide a preliminary indication of the importance of social interaction, an issue that could be explored further with more comprehensive sets of indices.

\section{DISCUSSION}

This study utilized the prePIRLS 2011 South African results to test Vygotsky's social interaction theory. Evidence was provided for the effect of parents who engage with 
their children in talking about school and checking homework, the school's emphasis on academic success, teachers' rating of success in implementing the curriculum and students' clarity on what their teachers expect from them as indicators of the social environment in which learning takes place.

Findings from the current study provide evidence for the significant social dimension of parents and teachers (when controlling for background factors) in predicting increased reading literacy achievement scores. For all the variables used in the current study, statistical significance was found at the 0.01 level, where an absence of interaction with the child in either parents who do not engage in homework activities or talking about school, or teachers who do not successfully implement the curriculum or make their expectations clear to students meant substantially lower reading literacy achievement scores.

The social aspect of the child's development therefore emphasises the fact that classrooms should be redefined as 'learning communities', as stated by Graves (2008). The classroom needs to become a curricular space in the form of a learning community. In these communities, teachers and students alike have something to contribute and something to learn. In reconceptualising the classroom as a community of practice, knowledge and expertise are distributed among participants in co-producing knowledge with a joint purpose that is pursued and negotiated together. While the results of our analysis supports the theoretical underpinnings of Vygotsky's social interaction theory, the different role players in the child's teaching and learning environment should not be seen in isolation from one another. As stated by Jeynes (2005), teachers themselves are influenced by parental involvement. Teachers play a major role in the grading and assessment of students in the classroom and their perceptions of a child can be greatly influenced by the degree of parental involvement. Thus, the social environment in which the student learns means that there should be a positive relationship between the teacher and the parents, a sense of teamwork between the teacher and the parent, increased communication between schools and parents and acknowledgement by the school and teachers of parental efforts. With the increasing diversity in South African classrooms, and persistently poor performance in national and international assessment programmes, instruction through the lens of sociocultural theory may assist teachers to teach literacy as a situational specificity in specific contexts, where students could ultimately negotiate multiple literacies in multiple contexts. In this manner, results of large-scale assessment programmes should be interpreted applying the lens of social interaction theory in terms of consideration to the local context, the purpose of the test and the policy context in which the testing took place.

\section{REFERENCES}

Adunyarittigun, D. (1997). Effects of the parent volunteer program upon students' selfperception as a reader. University of Maryland: College Park.

Andrabi, T., Das, J., Khwaja, A.I., \& Zajonc, T. (2011). Do value-added estimates add value? Accounting for learning dynamics. American Economic Journal: applied Economics 3(3), 29-54. 
Bianchi, S. M., Robinson, J.P., \& Milkie, M. (2006). Changing rhythms of American family life. New York: Russell Sage Foundation.

Bradley, R. H. \& Corwyn, R. F. (2002). Socio economic status and child development. Annual Review of Psychology, 53, 371-399.

Brinkley, M., \& Kelly, D.L. (2003). A Comparison of the NAEP and PIRLS Fourth Grade Reading Assessments. Retrieved July 7, 2004 from: http://nces.ed.gov/pubsearch/pubsinfo.asp?pubid=200310

Cunha, F., Heckman, J. J., Lochner, L., \& Masterov, D. V. (2006). Interpreting the evidence on life cycle skill formation. In: The Handbook of the Economics of Education, Volume 1. Eric A. Hanushek and Finis Welch (eds). Amsterdam: North Holland.

Deming, D. J., Hastings, J., Kane, T., \& Staiger, D. (2014). School Choice, School Quality and Postsecondary Attainment. American Economic Review, 104(3), 991-1013.

Diamond, J. B., Randolph, A., \& Spillane, J. P. (2004). Teachers' expectations and sense of responsibility for student learning: The importance of race, class and organizational habitus. Anthropology and Education Quarterly, 35(1), 75-98.

Donald, D., Condy, J., \& Forrester, J. (2003). Literacy development: Lessons learned from a pilot project in South Africa. The Reading Teacher, 56(5), 484-492).

Edwards, S. (2003). New directions: Charting the paths for the role of sociocultural theory in early childhood education and curriculum. Contemporary Issues in Early Childhood, 4(3), 251-265.

Edwards, V. J., Anda, R. F., Dube, S. R., Dong, M., Chapman, D. F., \& Felitti, V. J. (2005). The wide-ranging health consequences of adverse childhood experiences. In: K Kendall-Tackett and S Giacomoni, eds. Victimization of Children and Youth: Patterns of Abuse, Response Strategies. Kingston, NJ; Civic Research Institute.

Ford, D. H., \& Lerner, R. M. (1992). Developmental systems theory: An integrative approach. Thousand Oaks: Sage Publications.

Frank, E., \& Rosen, M. (2008). On the importance of parental participation for student achievement in reading literacy. Paper presented at the $3^{\text {rd }}$ IEA International Research Conference, Taipei, Taiwan.

Frost, J., Madsbjerg, S., Niedersee, J., Olofsson, A., \& Sorensen, P.M. (2005). Semantic and phonological skills in predicting reading development: From 3-16 years of age. Dyslexia, 11, 79-92.

Fuchs, T., \& Woessmann, L. (2004). What accounts for international differences in student achievement? A re-examination using PISA data. CESifo Working Paper No. 1235 . 
Geske, A., \& Ozola, A. (2008). Different influences of contextual educational factors on boys' and girls' reading achievement. Paper presented at the $3^{\text {rd }}$ IEA International Research Conference, Taipei, Taiwan.

Gonzalez-DeHass, A. R., Willems, P. P., \& Holbein, M. F. D. (2005). Examining the relationship between parental involvement and student motivation. Educational Psychology Review, 17(2), 99-123.

Graves, K. (2008). The language curriculum: A social contextual perspective. Language teaching, 41, 147-181.

Hansen, M., \& Quintero, D. (2017). Analysing the 'homework gap' among high school students. Retrieved November 15, 2017 from: https://www.brookings.edu/blog/browncenter-chalkboard/2017/08/10/analyzing-the-homework-gap-among-high-schoolstudents/

Heckman, J. J., Stixrud, J., \& Urzua, S. (2006). The effects of cognitive and noncognitive abilities on labor market outcomes and social behaviour. Journal of Labor Economics, 24(3), 411-482.

Hiebert, E. H. (1991). Introduction: In E. H. Hiebert (Ed.). Literacy for a Diverse Society: Perspectives, practices and policies. New York: Teachers College Press.

Howie, S. J., Van Staden, S., Tshele, M., Dowse, C., \& Zimmerman, L. (2012). South African children's reading literacy achievement summary report. Pretoria: Centre for Evaluation and Assessment.

Howie, S. J., Combrinck, C., Roux, K., Tshele, M., Mokoena, G. M., \& McLeod Palane, N. (2017). PIRLS Literacy2016: South African Highlights Report. Pretoria: Centre for Evaluation and Assessment.

Jeynes, W. H. (2005). A meta-analysis of the relation of parental involvement to urban elementary school student academic achievement. Urban Education, 40(3), 237-269.

Kozulin, A. (2002). Sociocultural theory and the mediated learning experience. SAGE Social Science Collections, 23(1), 7-35.

Landis, D. (2003). Reading and writing as social, cultural practices: Implications for literacy education. Reading and Writing Quarterly, 19, 281-307.

Lee, V. E., Zuze, T. L., \& Ross, K. N. (2005). School effectiveness in 14 Sub-Saharan African countries: Links with $6^{\text {th }}$ graders' reading achievement. Studies in Educational Evaluation, 31, 207-246.

Linnakyla, P., Malin, A., \& Taube, K. (2004). Factors behind low reading literacy achievement. Scandinavian Journal of Educational Research, 48(3). 231-249.

McLanahan, S. (2004). Diverging destinies: How children are faring under the second demographic transition. Demography, 41(4), 607-627. 
Mercer, N., \& Howe, C. (2012). Explaining the dialogic process of teaching and learning: The value and potential of sociocultural theory. Learning, Culture and Social Interaction (1), 12-21.

Mullis, I. V. S., Martin, M. O., Kennedy, A. M., Trong, K. L., \& Sainsbury, M. (2009). PIRLS 2011 Assessment framework. Boston College: TIMSS and PIRLS International Study Center.

Patall, E. A., Cooper, H., \& Robinson, J. C. (2008). Parent involvement in homework: A research synthesis. Review of Educational Research, 78(4), 1039-1101.

Prinsloo, M., \& Stein, P. (2004). What's inside the box? Children's early encounters with literacy in South African classrooms. Perspectives in Education, 22(2), 67-84.

Rubie-Davis, C., Hattie, J., \& Hamilton, R. (2006). Expecting the best for students: Teacher expectations and academic outcomes. British Journal of Educational Psychology, 76, 429-444.

Saegert, S., \& Winkel, G. H. (1990). Environmental Psychology. Annual Review of Psychology, 41(1), 441-477.

Triplett, C. F. (2007). The social construction of 'Struggle': Influences of school literacy contexts, curriculum and relationships. Journal of Literacy Research, 39(1), 95-126.

Van Daal, V., Begnum, C. A., Solheim, R. G., \& Ader, H. (2008). Nordic comparisons in PIRLS 2006. Paper presented at the $3^{\text {rd }}$ IEA International Research Conference, Taipei, Taiwan.

Van Staden, S. (2011). Reading between the lines: Contributing factors that affect Grade 5 learner reading performance. $\mathrm{PhD}$ thesis. Pretoria: University of Pretoria.

Vygotsky, L. S. (1962). Thought and language. Cambridge: MIT Press.

Vygotsky, L. S. (1978). Mind in Society. Cambridge: Harvard University Press. 